\title{
Aus der Brot- und Reiseapotheke
}

\section{Erhard Taverna}

Dr. med., Mitglied der Redaktion

Industriell verarbeitete Lebensmittel füllen die Verkaufsregale. Enzyme und andere Ingredienzien bestimmen Textur, Kochzeit, Volumen, Wasseraufnahme, Geschmack und Haltbarkeit von Lebensmitteln. Wir konsumieren seit vielen Jahren Folsäure im Mehl, Jod im Salz und Fluor im Trinkwasser. Bei der Verarbeitung von Lebensmitteln gehört das Familienunternehmen Bühler in Uzwil, Kanton St. Gallen, mit fast 11000 Mitarbeitern und Niederlassungen in 140 Ländern zu den ganz Grossen. 65\% der Weltproduktion von Weizen, 60\% von Schokolade und 30\% von Reis werden mit Maschinen des Ostschweizer Unternehmens zu einer Vielzahl von Produkten verarbeitet.

\section{Grundnahrungsmittel anreichern und Leben retten}

Präzise Mikrodosiergeräte ermöglichen eine exakte Anreicherung von Grundnahrungsmitteln mit Vitaminen und Mineralstoffen, die das Schicksal von Millionen Menschen positiv beeinflussen. Mit dieser sogenann-

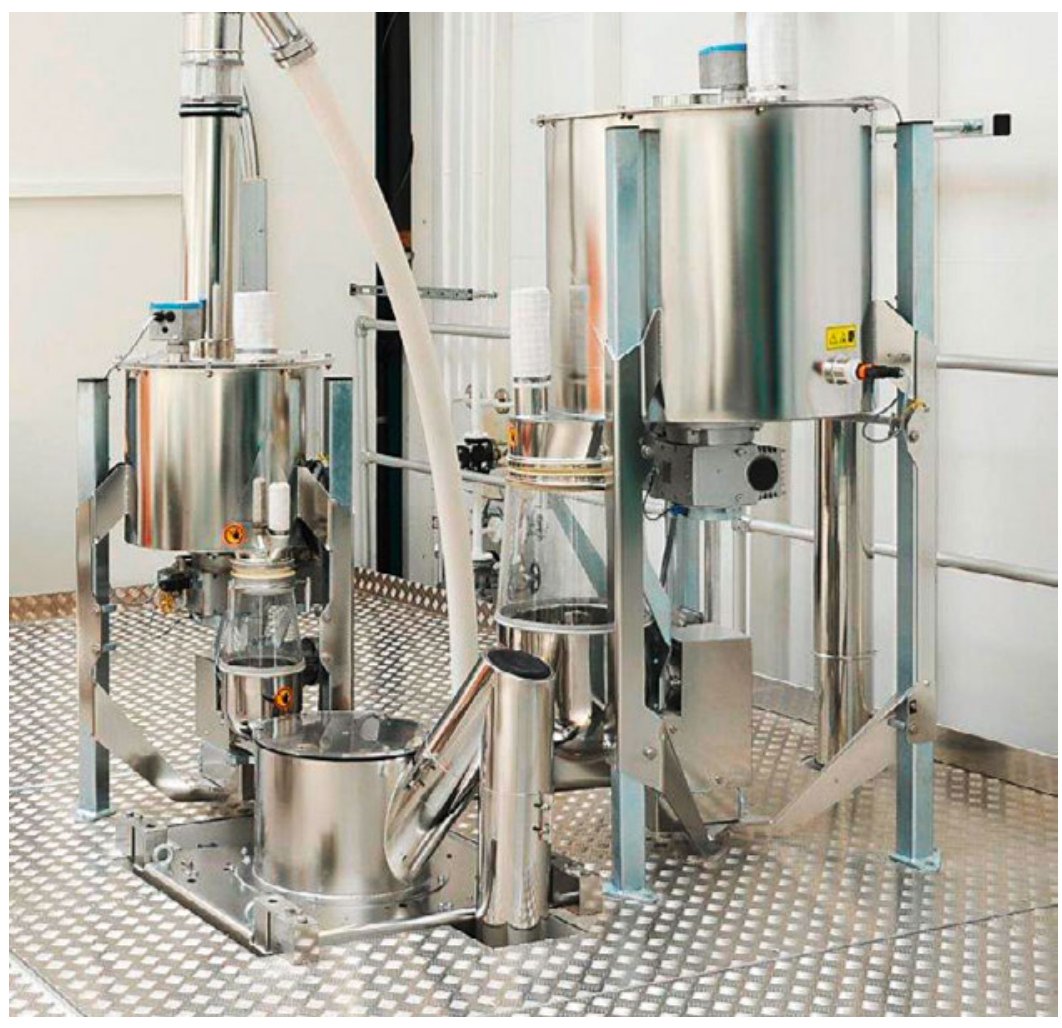

«Bühler Dosiergerät installiert.» ten Fortifizierung lassen sich Unter- und Fehlernährung wirkungsvoll bekämpfen. Eisenmangel ist die Ursache der Hälfte aller Anämien, Jodmangel führt zu Störungen des Wachstums und des Zentralnervensystems, Zinkmangel verursacht unter anderem Hypogonadismus, kognitive Störungen und schwächt die Immunabwehr. Zu wenig Vitamine A, D, alle B und die Folate sind eine chronische Ursache von Missbildungen und schweren Krankheiten bei Neugeborenen, Kindern und Müttern vor allem in Ländern der Dritten Welt. Zahlreiche Staaten, die WHO und private Organisationen (sogenannte NGOs) versuchen mit grossen Programmen und zum Teil enormen Ressourcen, die Ernährungssicherheit für Menschen weltweit zu verbessern. Bühler liefert zum Beispiel im Rahmen des britischen Food Fortification Programme über 1000 Mikrodosiergeräte nach Pakistan. Insgesamt können rund 350 Getreidemühlen, etwa die Hälfte aller Mühlen in Pakistan, zukünftig Weizenmehl mit Eisen, Folsäure, Vitamin $\mathrm{B}_{12}$ und Zink anreichern, um daraus Grundnahrungsmittel wie die Fladenbrote Roti oder Chapati herzustellen.

\section{Seit 2017 der Marktführer in der Reisverarbeitung}

Über zwei Milliarden Menschen leben vor allem vom Grundnahrungsmittel Reis. Beim Verarbeiten des Reiskorns gehen wertvolle Mikronährstoffe und Vitamine verloren, und Reiskörner werden teilweise zerbrochen. Dieser sogenannte broken rice hat eine mindere Qualität und wird oft als Tierfutter verwendet oder als billige Alternative gegessen. Durch HeissextrusionsTechnologie lassen sich aus diesem Nebenprodukt neue Reiskörner mit verschiedener Textur und Form herstellen. Diese Reiskörner werden bei der Extrusion mit Mineralstoffen und Vitaminen angereichert und dem traditionellen weissen Reis als recomposed rice $\mathrm{zu}^{-}$ gemischt. Dieses Verfahren verbessert nicht nur die Ökobilanz, sondern wertet auch den Nährstoffgehalt des weissen Reises deutlich auf.

\section{Neuste Technologien im Bakery Innovation Center}

Es sind mannshohe, chromblitzende Geräte verschiedener Ausführungen, welche die Besucher in Uzwil 
im Grain und Bakery Innovation Center zu sehen bekommen. Müller und Bäcker aus allen Ländern lernen hier die neuen Backtechnologien kennen. Sie büffeln die theoretischen Grundlagen und üben alle Fertigungsschritte vom Rohmaterial bis zum Endprodukt. Lagerstabile Vorteige für unterschiedlichste Backwaren, mineralreiche Sauerteige oder glutenfreie Produkte sind ein Megatrend. Dabei sind jedoch traditio-

\section{Ein neues Feld eröffnet sich Bühler in der industriellen Verarbeitung von Insekten.}

nelle Vorlieben und Eigenheiten zu berücksichtigen, vom Fladenbrot in Indien bis zur Tortilla in Mittelamerika. Kleinste Geschmacks-, Geruchs- oder Texturveränderungen können dazu führen, dass auch einwandfreie technische Lösungen vom Konsumenten nicht akzeptiert werden - oder eben doch.

\section{Proteinmehl aus Insekten}

Ein neues Feld eröffnet sich Bühler in der industriellen Verarbeitung von Insekten. Bühler bietet in Zusammenarbeit mit Protix-Technologie und Prozess-Know-how für Insektenverarbeiter an. Die erste Anlage in Europa wird für Protix in den Niederlanden Proteine aus den Larven der Schwarzen Soldatenfliege produzieren. Vorläufig als Futtermittel für Fische und Geflügel, langfristig wird es wohl auch auf unseren Tellern landen.

\section{Neuste Technologie für feinste Schokolade}

Das Familienunternehmen ist seit Generationen, zusammen mit illustren Pionieren wie Cailler, Nestlé und Lindt, mit der Produktion von Schokolade verbunden. Die neuste Innovation ist der ChocoBotic, eine integrierte Robotertechnologie für eine noch effizientere Produktion von feinster Schokolade. Vielleicht ist es kein Zufall, dass Herr und Frau Schweizer Weltmeister im Verzehr von Schokolade sind. Gemäss Studien steigert das Phenylethylamin der Kakaobohne den Endorphinspiegel. Ein Kick, der vier Mal länger dauern soll, als ein leidenschaftlicher Kuss. Auch da ist die Technologie von Bühler nicht mehr wegzudenken.

Bildnachweis

zVg von Bühler 